\title{
Validasi modul peduli: pelatihan asertivitas anti-bullying
}

\section{Udi Rosida Hijrianti ${ }^{1}$}

\begin{abstract}
This study was conducted to validate the Anti-bullying Assertiveness Training Module called PEDULI module. The PEDULI module aims to provide knowledge and understanding to adolescents about bullying and to train them to be assertive in everyday life in order to avoid bullying behavior. There are two hypotheses tested in this study, namely first, the PEDULI module has good content validity. The results of the evaluation of the three expert judgments show the content validity coefficient value of $86 \%-93 \%$. The second hypothesis is that there is a significant increase in assertiveness in the experimental group subjects compared to the control group subjects. The results of statistical tests using Mixed ANOVA analysis showed that the assertiveness score in the experimental group was significantly higher than the control group $(F=11,699$ and $p=0.002 ; p<0.05)$ and the assertiveness score after training in the experimental group was significantly higher than before the training $(F=4.182$ and $p=0.021 ; p<0.05)$. Based on these results, it can be concluded that the Anti-bullying Assertiveness Training module (PEDULI) is declared content valid and empirically valid in its application to 14 students in the experimental group.
\end{abstract}

\section{Keywords}

Anti-bullying, assertiveness training, adolescent, senior high school student

\section{Pendahuluan}

Jumlah kejadian bullying dari tahun ke tahun menunjukkan angka yang memprihatinkan baik di luar dan dalam negeri. Bahkan Indonesia sudah masuk kategori "darurat bullying di sekolah" yaitu hampir setiap sekolah di Indonesia terjadi bullying dalam bentuk bullying verbal maupun psikologis/mental (Rini, 2014).

Bullying adalah subtipe dari perilaku agresif, yaitu seseorang atau sebuah kelompok berulang kali melakukan serangan, menghina, dan atau mengucilkan orang yang relatif tidak berdaya (Salmivalli, 2009). Mayoritas penelitian tentang bullying telah dilakukan di sekolah-sekolah yang berfokus pada anak-anak dan remaja (Boulton et al., 1994; Salmivalli, 2009; Salmivalli et al., 1996). Hasil penelitian tersebut adalah diketahui bahwa banyak siswa sekolah dasar dan menengah yang terlibat dalam bullying baik sebaik sebagai pelaku, korban, atau keduanya yaitu menjadi pelaku karena pernah menjadi korban (Salmivalli, 2009; Sari, 2015).

Bullying menyebabkan risiko psikososial dan penyesuaian akademik yang serius pada korban (Erath et al., 2008; Hawker \& Boulton, 2000; Isaacs et al., 2008; Salmivalli, 2009; Salmivalli \& Isaacs, 2005) dan pelakunya (Kaltiala-Heino et al., 2000; Nansel et al., 2004). Selain pada korban dan pelaku, terdapat bukti bahwa penonton yang hanya menyaksikan bullying juga dapat terpengaruh negatif (Nishina \& Juvonen, 2005).
Faktor-faktor psikososial yang menyebabkan terjadinya bullying ini antara lain: 1) Perilaku membangkang karena pengaruh teman yang nakal, 2) Sikap kurang serius di sekolah, 3) Miskin kontrol diri sehingga bertindak agresif dan impulsif, 4) Kurang yakin untuk bertindak tegas (asertif) terhadap bullying (Ando et al., 2005; Novalia \& Dayakisni, 2013). Temuan ini memberikan pemahaman bahwa perilaku tidak asertif akan menempatkan anak-anak pada risiko menjadi korban bullying di sekolah (Fox \& Boulton, 2005, 2006).

Sehubungan dengan hal tersebut, asertivitas menurut Townend (1991) yaitu memiliki kepercayaan diri, bersikap positif pada diri sendiri dan orang lain dengan cara berkata terbuka, spontan, dan jujur. Asertivitas bukanlah mendapatkan apa yang diinginkan dengan mengorbankan orang lain, namun bagaimana mendapatkan apa yang diinginkan dengan cara terbuka tanpa merugikan orang lain, sehingga perilaku asertif dapat mereduksi tekanan emosional atau beban masalah yang dihadapi remaja.

Kemampuan bersikap asertif ini dapat dipelajari dan dikembangkan melalui pelatihan asertivitas. Fox \&

\footnotetext{
1 Universitas Muhammadiyah Malang

Korespondensi:

Udi Rosida Hijrianti, Fakultas Psikologi, Universitas Muhammadiyah Malang

Email: udi@umm.ac.id
} 
Boulton (2003) telah melakukan penelitian tentang social skill training atau disebut dengan pelatihan asertivitas yang terbukti dapat meningkatkan harga diri anak korban pemalakan. Penelitian tentang pelatihan asertivitas dalam kaitannya dengan bullying juga pernah dilakukan oleh Rini (2008) yang memperoleh hasil pelatihan asertif pada korban bullying sekolah dasar terbukti efektif untuk mengurangi frekuensi untuk ditindas. Selanjutnya, hasil penelitian Amawidyati (2010) menemukan bahwa pelatihan asertivitas dapat menurunkan frekuensi peristiwa bullying yang dialami oleh korban anak SD.

Mencermati pemaparan di atas, telah tergambar bahwa dibutuhkan sebuah tindakan pencegahan bullying terutama terhadap remaja yang kemampuan asertivitasnya rendah, karena mereka memiliki kerentanan menjadi korban bullying. Oleh karena itu, pada penelitian ini peneliti menyusun modul Pelatihan Asertivitas Anti-bullying (PEDULI) yang bertujuan untuk memberikan pengetahuan dan pemahaman pada remaja tentang bullying dan melatihkan cara bersikap asertif dalam kehidupan seharihari agar menghindari perilaku bullying. Modul PEDULI terdiri dari dua bagian utama, yaitu bagian pertama memberikan psikoedukasi tentang bullying dan bagian kedua memberikan pelatihan asertivitas.

Modul PEDULI pada bagian pertama memberikan psikoedukasi tentang bullying, sebagaimana hasil yang ditunjukkan oleh penelitian Craig et al. (2007) yaitu beberapa anak-anak dan pemuda (mulai usia 4 hingga 19 tahun) di Kanada telah termotivasi dengan kampanye pendidikan publik atau informasi tentang bullying. Peserta penelitian Craig et al. (2007) termotivasi melakukan sesuatu untuk menghentikan bullying atas dasar kebutuhan mereka sendiri dalam melakukan kontrol dan bersikap tegas atau sebagai reaksi emosional mereka terhadap bullying.

Modul PEDULI pada bagian kedua memberikan pelatihan asertivitas. Materi asertivitas dalam modul ini disusun peneliti dengan mengacu konsep yang dikemukakan oleh Townend (1991). Materi pelatihan asertivitas dalam modul PEDULI ini terdiri dari lima topik, yaitu: 1) Membangun kesadaran diri, 2) Meningkatkan kepercayaan diri, 3) Melakukan relaksasi, 4) Melakukan visualisasi positif, serta 5) Mampu mengekspresikan pikiran dan perasaan.

Modul PEDULI ini dilakukan dengan menggunakan prinsip-prinsip experiential learning atau pembelajaran berbasis pengalaman yang menuntut taraf keterlibatan pribadi yang tinggi dari pihak pembelajar (Supratiknya, 2011). Kolb et al. (1999) mengungkapkan bahwa experiential learning adalah proses membangun pengetahuan yang melibatkan siklus empat tahap pengalaman atau aktivitas yaitu: 1) Concrete Experience (CE), 2) Reflective Observation (RO), 3) Abstract Conceptualization (AC), dan 4) Active Experimentation (AE). Tahap Concrete Experience yaitu menggunakan pengalaman yang sudah dilalui peserta atau pengalaman yang disediakan untuk pembelajaran yang lebih lanjut. Tahap Reflective Observation yaitu mendiskusikan pengalaman para peserta yang telah dilalui atau saling berbagi reaksi dan observasi yang telah dilalui. Tahap Abstract Conceptualization adalah menemukan tren yang umum dan kebenaran dalam pengalaman yang telah dilalui peserta atau membentuk reaksi pada pengalaman yang baru menjadi sebuah kesimpulan atau konsep yang baru. Tahap Active Experimentation yaitu modifikasi perilaku lama dan mempraktekkan pada situasi keseharian para peserta (Purnami \& Rohayati, 2013).

Dalam membuat sebuah modul harus didasarkan pada model-model tertentu untuk memastikan bahwa modul tersebut akan berdampak kepada penggunanya, selain perlu ditulis dengan baik (Ahmad et al., 2011). Noah dan Ahmad (Jalil \& Mahfar, 2016) menambahkan bahwa penting untuk mengikuti langkah-langkah yang telah ditetapkan dalam proses konstruksi modul untuk memastikan kualitas modul itu sendiri. Pembuatan modul PEDULI ini mengacu pada konstruksi modul Model Russell (Ahmad et al., 2011). Model ini telah cukup sering digunakan untuk mengkonstruksi berbagai jenis modul misalnya dalam penelitian Ahmad et al. (2009) dan Ahmad et al. (2011).

Berdasarkan pemaparan yang telah diuraikan di atas, maka penelitian ini bertujuan untuk memvalidasi modul Pelatihan Asertivitas Anti-bullying (PEDULI). Validasi dilakukan melalui dua tahap yaitu pertama, uji validitas isi dan yang kedua, uji empirik atau penelitian eksperimen terhadap modul PEDULI. Hasil penelitian ini diharapkan bermanfaat dalam memberikan sumbangan model prevensi bullying melalui peningkatan asertivitas siswa yang dapat diterapkan oleh psikolog atau trainer dengan latar belakang psikologi. Hal ini karena kualifikasi yang diperlukan sebagai fasilitator modul PEDULI adalah seseorang yang memiliki kompetensi yang memadai di bidang psikologi.

\section{Hipotesis Penelitian}

Hipotesis yang diajukan dari penelitian ini ada dua, yaitu:

(a) Modul Pelatihan Asertivitas Anti-bullying (PEDULI) memiliki validitas isi yang baik.

(b) Terdapat perubahan peningkatan asertivitas yang signifikan pada subjek kelompok eksperimen dibandingkan dengan subjek pada kelompok kontrol.

\section{Metode}

\section{Variabel Penelitian}

Variabel dalam penelitian ini terdiri dari variabel independen yaitu Pelatihan Asertivitas Anti-bullying dan variabel dependen yaitu asertivitas.

\section{Subjek Penelitian}

Subjek dalam penelitian ini memiliki karakteristik: 
(a) Siswa Sekolah Menengah Atas (SMA) berjenis kelamin pria dan wanita.

(b) Memiliki hasil seleksi dari skor skala asertivitas berada pada kategori sedang.

(c) Bersedia secara sukarela berpartisipasi pada proses penelitian yang dibuktikan melalui kesediaannya mengisi informed consent penelitian.

Subjek yang memenuhi karakteristik di atas dan bersedia menjadi peserta penelitian berjumlah 28 siswa, terdiri dari 14 siswa SMAN V di kelompok eksperimen (KE) dan 14 siswa SMAN VII di kelompok kontrol (KK).

\section{Instrumen Penelitian}

Skala asertivitas Skala ini terdiri dari 32 aitem yang mencakup 4 ciri asertif, yaitu a) Kemampuan memulai, melanjutkan, dan mengakhiri suatu pembicaraan dengan sukses; b) Kemampuan mengatakan "tidak" terhadap sesuatu yang tidak disetujui; c) Kemampuan mengajukan permintaan atau bantuan kepada orang lain jika memang membutuhkan bantuan; d) Kemampuan menyatakan perasaannya, baik perasaan yang menyenangkan maupun yang kurang menyenangkan.

Cek manipulasi pengetahuan bullying Instrumen ini terdiri dari 15 aitem dengan format jawaban benar-salah disusun oleh peneliti berdasarkan materi yang ada dalam modul PEDULI.

\section{Intervensi}

Bentuk intervensi dalam penelitian ini adalah Pelatihan Asertivitas Anti-bullying (PEDULI) yang terdiri dari 8 sesi dilaksanakan sebanyak 4 kali pertemuan dengan durasi tiap pertemuan kurang lebih 2 jam dalam periode 2 minggu. Sehingga, total waktu Pelatihan Asertivitas Antibullying ini adalah 8 jam. Sesi 1 dan 2 dilaksanakan pada pertemuan pertama pelatihan; sesi 3 dan 4 dilaksanakan pada pertemuan kedua; sesi 5 dan 6 dilaksanakan pada pertemuan ketiga; serta sesi 7 dan 8 dilaksanakan pada pertemuan keempat.

\section{Prosedur}

\section{Tahap persiapan penelitian}

1. Menyusun modul Pelatihan Asertivitas Antibullying (PEDULI)

2. Uji validitas isi modul Pelatihan Asertivitas Antibullying (PEDULI) Uji validitas isi terhadap modul PEDULI melibatkan ahli/expert judgement sebanyak tiga orang. Para ahli tersebut adalah psikolog lulusan Magister Profesi Psikologi UGM yang memiliki kompetensi dan pengalaman membuat modul pelatihan.

3. Perbaikan modul berdasarkan masukan expert judgement
4. Briefing pada fasilitator dan observer

5. Uji coba modul Pelatihan Asertivitas Anti-bullying. Uji coba pelatihan dilaksanakan pada tanggal 9 dan 10 Oktober 2020 pukul 09.00-13.00 bertempat di biro EP milik fasilitator. Subjek uji coba pelatihan ini berjumlah empat orang siswa SMA. Hasilnya, semua subjek mengalami peningkatan skor saat posttest baik pada asertivitas maupun pengetahuan bullying. Rerata gain score pada asertivitas adalah sebesar 16,5 poin, sementara pada pengetahuan bullying sebesar 26,64 poin.

6. Penyusunan alat ukur

7. Uji validitas dan reliabilitas alat ukur Uji validitas isi skala asertivitas dilakukan dengan meminta penilaian pada 16 mahasiswa magister profesi psikologi. Selanjutnya, dihitung koefisien validitas isinya menggunakan Aiken's V. Hasilnya diperoleh rerata nilai $\mathrm{V}$ untuk skala asertivitas sebesar 0,82645. Hasil try out skala asertivitas yang dilakukan pada 98 siswa SMA menghasilkan nilai koefisien reliabilitas alpha cronbach sebesar 0,903.

Selanjutnya, uji validitas isi cek manipulasi pengetahuan bullying dilakukan dengan meminta penilaian pada 10 mahasiswa magister profesi psikologi. Hasilnya diperoleh rerata nilai $\mathrm{V}$ untuk cek manipulasi pengetahuan bullying sebesar 0,828 .

Tahap pelaksanaan penelitian Pelatihan diawali dengan skrining/pretest mengisi skala asertivitas di masingmasing sekolah kelompok eksperimen dan kontrol. Hasil dari skrining tersebut diperoleh daftar nama siswa yang memiliki skor asertivitas pada kategori sedang. Selanjutnya, peneliti menawarkan untuk mengisi informed consent pada subjek terpilih tersebut.

Kelompok eksperimen mendapatkan perlakuan Pelatihan Asertivitas Anti-bullying yang dilaksanakan sebanyak 4 kali pertemuan dalam periode 2 minggu. Setelah pelatihan selesai dilakukan, subjek di KE dan KK memperoleh pengukuran posttest. Kemudian proses follow up dilakukan 4 minggu setelah pelatihan selesai dilaksanakan, yaitu pada subjek KE dilakukan dengan mengisi skala asertivitas dan cek manipulasi pengetahuan bullying kembali, serta FGD mengenai hal-hal yang diperoleh selama pelatihan. Rentang waktu follow up 4 minggu setelah akhir pelaksanaan perlakuan ini menyesuaikan dengan penelitian Lin et al. (2004) dan penelitian Lee \& Crockett (1994). Berikut jadwal pelaksanaan Pelatihan Asertivitas Anti-bullying pada subjek kelompok eksperimen dan kontrol.

\section{Hasil \\ Uji validitas isi modul Pelatihan Asertivitas Anti-bullying (PEDULI)}

Teknik persentase yang digunakan untuk menganalisis hasil validitas isi ketiga ahli / expert judgement dalam 
Tabel 1. Timeline Pelaksanaan Penelitian pada Kelompok Eksperimen dan Kelompok Kontrol

\begin{tabular}{|c|c|c|}
\hline \multirow{2}{*}{ Tahapan } & \multicolumn{2}{|l|}{ Tanggal Pelaksanaan } \\
\hline & Kelompok Eksperimen & Kelompok Kontrol \\
\hline Pretest & 15 Oktober 2020 & 17 Oktober 2020 \\
\hline Pertemuan 1 (Pembukaan dan Mengenal bullying) & 20 Oktober 2020 & \\
\hline $\begin{array}{l}\text { Pertemuan } 2 \text { (Membangun Kesadaran Diri dan Meningkatkan } \\
\text { Kepercayaan Diri) }\end{array}$ & 22 Oktober 2020 & \\
\hline Pertemuan 3 (Mampu Mengekspresikan Pikiran dan Perasaan) & 27 Oktober 2020 & \\
\hline $\begin{array}{l}\text { Pertemuan } 4 \text { (Relaksasi, Visualisasi Positif, dan Penutupan Kegiatan } \\
\text { \& Evaluasi) }\end{array}$ & 29 Oktober 2020 & \\
\hline Posttest & 5 November 2020 & 7 November 2020 \\
\hline Follow up & 26 November 2020 & 28 November 2020 \\
\hline
\end{tabular}

Tabel 2. Skor Pretest, Posttest, dan Follow up Skala Asertivitas Kelompok Eksperimen

\begin{tabular}{llllllll}
\hline \multirow{2}{*}{ Subjek } & \multicolumn{2}{l}{ Skor Asertivitas } & \multicolumn{7}{l}{ Kategori } & \multirow{2}{*}{ Keterangan } \\
\cline { 2 - 6 } & Pretest & Posttest & $\begin{array}{l}\text { Follow } \\
\text { up }\end{array}$ & Pretest & Posttest & Follow up & \\
\hline MRA & 116 & 121 & 121 & Sedang & Tinggi & Tinggi & Naik Grade \\
HIC & 116 & 125 & 125 & Sedang & Tinggi & Tinggi & Naik Grade \\
MF & 116 & 122 & 126 & Sedang & Tinggi & Tinggi & Naik Grade \\
WRAR & 116 & 130 & 126 & Sedang & Tinggi & Tinggi & Naik Grade \\
RFH & 114 & 106 & 124 & Sedang & Sedang & Tinggi & Naik Grade \\
FNP & 114 & 125 & 124 & Sedang & Tinggi & Tinggi & Naik Grade \\
SR & 112 & 125 & 123 & Sedang & Tinggi & Tinggi & Naik Grade \\
ACU & 109 & 119 & 118 & Sedang & Tinggi & Tinggi & Naik Grade \\
RVW & 107 & 101 & 106 & Sedang & Sedang & Sedang & Stabil \\
NLM & 103 & 118 & 122 & Sedang & Tinggi & Tinggi & Naik Grade \\
LAF & 100 & 98 & 85 & Sedang & Sedang & Sedang & Stabil \\
SNI & 96 & 114 & 108 & Sedang & Sedang & Sedang & Stabil \\
KBD & 91 & 92 & 89 & Sedang & Sedang & Sedang & Stabil \\
HSP & 92 & 102 & 104 & Sedang & Sedang & Sedang & Stabil \\
\hline
\end{tabular}

penelitian ini mengikuti saran dari Tuckman dan Waheed (Ahmad et al., 2009) dan Nordin (Ahmad et al., 2009), yaitu tingkat pencapaian yang lebih dari $70 \%$ bisa dikategorikan memiliki validitas isi yang tinggi. Ratarata validitas isi dari ketiga ahli adalah $86 \%-93 \%$, nilai presentase ini telah melampaui tonggak yang ditetapkan oleh Russell (Ahmad et al., 2009). Hal ini berarti ketiga ahli telah mengakui bahwa modul PEDULI memiliki validitas isi yang baik, serta dapat menunjukkan pula bahwa modul PEDULI telah sesuai dengan tujuan dan layak untuk digunakan.

\section{Uji empirik/ penelitian eksperimen terhadap modul Pelatihan Asertivitas Anti-bullying (PEDULI)}

Hasil penelitian dilakukan secara kuantitatif melalui Uji Prasyarat Analisis dan Uji Mixed ANOVA yang akan diuraikan berikut ini.

Uji Normalitas Uji normalitas dilakukan untuk mengetahui apakah distribusi dari data pengukuran variabel yang diteliti menyebar secara normal atau tidak. Uji normalitas dilakukan dengan menggunakan uji Kolmogorof-Smirnov Test dengan SPSS. Kriteria pengujiannya yaitu jika nilai signifikansi $\mathrm{p}>0,05$ maka data berdistribusi normal, sedangkan jika $\mathrm{p}<0,05$ maka data berdistribusi tidak normal (Sudjana, 1991). Hasil uji normalitas data pada asertivitas dan hasil uji normalitas data pada pengetahuan bullying menunjukkan nilai Sig lebih dari 0,05 (p > 0,05 ) yang berarti sebaran data asertivitas dan pengetahuan bullying pada saat pretest, posttest, maupun follow up di kelompok eksperimen dan kontrol berdistribusi normal.

Uji Homogenitas Uji homogenitas dilakukan untuk melihat apakah varian data memiliki sifat yang homogen atau tidak. Uji homogenitas dilakukan dengan menggunakan Levene's Test dengan SPSS. Kriteria pengujiannya, jika besar $\mathrm{p}>0,05$ maka varian data dikatakan homogen, sedangkan jika besar $\mathrm{p}<0,05$ maka varian data dikatakan tidak homogen. Hasil uji homogenitas data pada asertivitas dan pengetahuan bullying menunjukkan bahwa semua nilai Sig lebih dari $0,05(\mathrm{p}>0,05)$ yang berarti varians data asertivitas dan pengetahuan bullying di kelompok eksperimen dan kontrol adalah homogen.

\section{Uji Mixed ANOVA}

Pada tabel 2 di bawah ini dapat dilihat bahwa rerata skor asertivitas pada kelompok eksperimen semakin meningkat saat posttest dan follow up, sementara rerata skor asertivitas kelompok kontrol semakin menurun. Hasil 
ini memperkuat hipotesis bahwa adanya peningkatan asertivitas pada kelompok eksperimen setelah mengikuti Pelatihan Asertivitas Anti-bullying dibandingkan dengan kelompok kontrol.Hasil pengujian menggunakan Pairwise Comparisons menunjukkan bahwa perubahan asertivitas pada KE adalah signifikan (mean difference/selisih rerata $=-6,857 ; \mathrm{p}=0,008(\mathrm{p}<0,05)$. Sedangkan perubahan asertivitas pada $\mathrm{KK}$ adalah tidak signifikan $(\mathrm{MD}=$ $0,143 ; \mathrm{p}=0,953$ ( $\mathrm{p}>0,05)$. Hal ini menunjukkan bahwa Pelatihan Asertivitas Anti-bullying efektif dalam meningkatkan asertivitas peserta KE.

Lebih lanjut, hasil uji Mixed ANOVA menunjukkan skor asertivitas pada kelompok eksperimen lebih tinggi secara signifikan dibandingkan kelompok kontrol (between group) dengan $\mathrm{F}=11,699, \mathrm{p}=0,002(\mathrm{p}<0,05)$ dan skor asertivitas sesudah pelatihan pada kelompok eksperimen lebih tinggi secara signifikan dibandingkan sebelum pelatihan (within group) dengan $\mathrm{F}=4,182, \mathrm{p}=$ $0,021(\mathrm{p}<0,05)$. Sementara itu, sumbangan efektif dari Pelatihan Asertivitas Anti-bullying adalah sebesar 26,4\% dalam peningkatan asertivitas subjek KE.

Kemudian hasil analisis terhadap cek manipulasi pengetahuan bullying menunjukkan bahwa terjadi peningkatan rerata pengetahuan bullying pada kelompok eksperimen. Selanjutnya dianalisis menggunakan One-Way Anova diperoleh nilai $\mathrm{F}=11,376$; Sig $0,000(\mathrm{p}<0,05)$ yang berarti rerata pengetahuan bullying saat pretest, posttest, dan follow up adalah berbeda. Oleh karena berbeda, maka perlu dilakukan uji analisis lanjut (Post Hoc). Berdasarkan Post Hoc Test diketahui pada kolom Mean Difference (perbedaan rata-rata) antara pretest dan posttest sebesar $-15,24429^{*} ; \mathrm{p}=0,001(\mathrm{p}<0,05)$ yang berarti perbedaan rerata antara pretest dan posttest adalah signifikan. Mean Difference antara pretest dan follow up sebesar $16,21000^{*} ; \mathrm{p}=0,000(\mathrm{p}<0,05)$ yang berarti perbedaan rerata antara pretest dan follow up adalah signifikan. Mean Difference antara posttest dan follow up sebesar -0,96571; $\mathrm{p}=0,965(\mathrm{p}>0,05)$ yang berarti perbedaan rerata antara posttest dan follow up adalah tidak signifikan.

\section{Diskusi}

\section{Metode Konstruksi Modul Pelatihan Asertivitas Anti-bullying (PEDULI)}

Russell (Ahmad et al., 2009) memiliki pedoman yang perlu diikuti dalam proses konstruksi modul. Setiap pedoman yang disebutkan oleh Russell telah dianut oleh peneliti dalam proses konstruksi modul Pelatihan Asertivitas Antibullying (PEDULI). Russell menyatakan bahwa sebelum konstruksi modul, kelompok sasaran harus diketahui sebelumnya. Pada penelitian ini, kelompok sasaran adalah siswa SMA yang memiliki tingkat asertivitas sedang.

Selain itu, Russell menekankan identifikasi tujuan modul. Pada penelitian ini tujuan utama dari modul PEDULI adalah untuk memberikan pengetahuan dan pemahaman pada remaja tentang bullying dan melatihkan cara bersikap asertif dalam kehidupan sehari-hari agar menghindari perilaku bullying.

Russell selanjutnya menyebutkan bahwa setiap modul harus memiliki item pengukuran untuk mengidentifikasi tingkat prestasi/kinerja peserta. Pada modul PEDULI ini, lembar-lembar kerja telah dibuat berdasarkan tujuan masing-masing sesi yang dilakukan. Tujuan dari lembar kerja ini adalah untuk mengukur tingkat kinerja peserta setelah menyelesaikan sesi dalam modul.

Selain itu, fasilitator telah meminta penjelasan dan mewawancarai peserta untuk memperoleh pengetahuan tentang tingkat kinerja/prestasi, kemampuan, dan penguasaan peserta selama proses pelatihan dengan menggunakan modul. Selain itu, Russell menggarisbawahi bahwa modul perlu diatur berurutan dan dipasangkan dengan instrumen, bahan, atau media yang cocok sebagai penguat dan pelengkap. Modul PEDULI ini telah melalui penelaahan mendalam dari berbagai aspek termasuk pengaturan kegiatan dan bahan yang dianggap perlu dan tepat untuk digunakan.

Selanjutnya, modul yang dikonstruksi harus diujicobakan pada kelompok sasaran untuk mendapatkan masukan yang berguna dalam mengidentifikasi kekuatan dan kelemahan dari modul. Langkah ini telah dilakukan oleh peneliti melalui uji coba pelatihan pada empat orang siswa SMA. Tanggapan dan masukan dari subjek uji coba pelatihan telah diperhitungkan untuk perbaikan modul lebih lanjut dan untuk memastikan dampak praktis selama penelitian eksperimen.

Selanjutnya, Russell menunjukkan bahwa sebelum modul dapat digunakan/diterapkan harus ditentukan dulu validitas isi dan reliabilitasnya. Peneliti telah mengikuti saran dengan melibatkan tiga expert judgment untuk memberikan validitas isi. Singkatnya, tidak bisa disangkal bahwa modul PEDULI mematuhi pedoman dari Russell (Ahmad et al., 2011) dan secara tidak langsung modul PEDULI menjadi instrumen yang valid untuk digunakan pada siswa SMA.

Validitas Isi dari Modul Pelatihan Asertivitas Antibullying (PEDULI) Noeh dan Ahmad (Ahmad et al., 2011) menyatakan bahwa modul akan dianggap baik jika memiliki validitas isi yang baik. Metode yang digunakan untuk menentukan apakah modul ini memiliki validitas isi yang baik diambil dari pandangan Tuckman dan Waheed (Ahmad et al., 2011) dan Abu Bakar Nordin (Ahmad et al., 2011) yang menyatakan bahwa pencapaian tingkat $70 \%$ atau lebih telah menunjukkan pencapaian yang tinggi. Ketiga expert judgement validitas isi modul telah memberikan nilai evaluasi lebih dari $70 \%$. Berdasarkan nilai presentase sebesar $86 \%$ - 93\% menunjukkan bahwa modul PEDULI memiliki validitas isi yang baik.

Uji Empirik/ Penelitian Eksperimen terhadap Modul Pelatihan Asertivitas Anti-bullying (PEDULI) Russell (Ahmad et al., 2011) menyatakan bahwa modul harus mampu membawa individu ke perubahan positif. Hasil analisis statistik menunjukkan peningkatan asertivitas 
pada subjek kelompok eksperimen, yaitu Pelatihan Asertivitas Anti-bullying dapat menjelaskan 26,4\% varians peningkatan asertivitas subjek KE. Perubahan skor asertivitas subjek KE dapat dilihat pada 2.

Berdasarkan tabel 2 dapat dilihat perubahan kategori skor asertivitas subjek dari saat pretest, posttest, dan follow up. Akumulasi subjek yang mengalami peningkatan kategori asertivitas (pretest, posttest, ke follow up) ada sembilan subjek dan ada lima orang subjek yang tetap stabil pada kategori sedang. Adanya peningkatan rerata asertivitas pada kelompok eksperimen, baik pada saat posttest maupun follow up setelah diberikan Pelatihan Asertivitas Anti-bullying ini mendukung penelitian yang telah dilakukan oleh Setiono \& Pramadi (2005) dan (Weni Nur, 2012) yang menunjukkan adanya peningkatan perilaku asertif setelah diberinya pelatihan asertif.

Modul 'PEDULI' ini terdiri dari 8 sesi yaitu: (1) Pembukaan; (2) Pengetahuan bullying; (3) Membangun Kesadaran Diri; (4) Memiliki Kepercayaan Diri; (5) Mampu Mengekspresikan Diri; (6) Relaksasi; (7) Visualisasi positif; serta (8) Penutupan. Adapun materi-materi yang diberikan dalam modul 'PEDULI' terdiri dari: (a) Mengenal bullying; (b) Memahami berbagai sikap seseorang: Pasif, agresif, asertif; (c) Mengenali dan memahami sikap dan perilaku diri sendiri; (d) Memahami tentang potensi dan konsep diri sendiri dengan mengisi lembar kerja "Tentang Diriku" yang berisi tentang: Kelemahanku, Keunggulanku, Pikiran Negatif tentang Diriku, dan Pikiran Positif tentang Diriku; (e) Meningkatkan kepercayaan diri dengan mengisi lembar kerja "Daftar Karunia yang Membuatku Bersyukur”; (f) Permainan ekspresikan diri; (g) Memiliki kemampuan orang asertif dengan mempraktekkan bersama teman keempat ciri kemampuan yang dimiliki orang asertif; (h) Melakukan relaksasi; (i) Melakukan visualisasi positif. Berikut ini adalah ulasan masing-masing sesi.

Pada sesi Pengetahuan bullying dengan materi tentang "Mengenal bullying" telah memberikan efek meningkatkan pengetahuan dan pemahaman pada peserta tentang bullying. Berdasarkan hasil analisis One-Way Anova diketahui bahwa terjadi peningkatan rerata pengetahuan bullying secara signifikan setelah Pelatihan Asertivitas Anti-bullying selesai diberikan pada subjek kelompok eksperimen. Hasil ini mendukung penelitian Nugroho (2009); Sitasari (2012); Hasan et al. (2013); Perwitasari (2013) bahwa pelatihan Anti-bullying terbukti efektif meningkatkan pengetahuan merespon bullying. Hal ini juga didukung oleh hasil wawancara pada subjek MF setelah mendapat materi "Mengenal bullying", ia menjadi mengenali lebih dalam tentang bullying, NLM menjadi bisa lebih paham tentang bullying, dan RVW lebih bisa aware terhadap bullying baik pada diri sendiri dan orang lain.

Pada sesi Membangun Kesadaran Diri, peserta diajak untuk memahami berbagai sikap seseorang sehingga dapat mengenali dan memahami sikap dan perilaku diri sendiri. Tujuan sesi ini dapat tercapai dibuktikan dari hasil wawancara setelah mempelajari materi "Memahami berbagai sikap seseorang" menurut pengakuan HSP, ia menjadi bisa mengenali dirinya sendiri tentang bagaimana ia bersikap, sehingga jika masih buruk bisa diperbaiki. Selain itu, WRAR menjadi lebih bisa paham tentang perasaan dan sifat-sifat orang lain. NLM menambahkan, bahwa ia bisa belajar dan lebih mengerti tentang berbagai sikap seseorang, sehingga menurut RVW akan tidak mudah sakit hati. Serta menurut pengakuan FNP, ia menjadi tahu sikap apa yang seharusnya diperbuat pada orang lain. Selanjutnya setelah mempelajari materi "Mengenali dan memahami sikap dan perilaku diri sendiri" menurut pengakuan WRAR, ACU, dan SNI, mereka menjadi lebih bisa mengenali, mengerti, dan mengetahui lebih dalam tentang dirinya sendiri. RVW menambahkan manfaat telah mempelajari materi ini adalah supaya paham seperti apa diri kita dan seharusnya bagaimana, serta dapat memotivasi FNP untuk menjadi diri sendiri.

Townend (2007) menyebutkan bahwa kepercayaan diri dapat dibentuk setelah memiliki kesadaran diri. Oleh karena itu, pada sesi Memiliki Kepercayaan Diri dilakukan melalui memahami tentang potensi dan konsep dalam diri sehingga peserta dapat meningkatkan kepercayaan dirinya. Tujuan sesi ini dapat tercapai dibuktikan dari hasil wawancara setelah mempelajari materi "Memahami tentang potensi dan konsep diri sendiri" menurut pengakuan LAF, ia menjadi lebih bisa mengerti dan mengetahui lebih dalam tentang dirinya sendiri, karena ia menjadi tahu kelebihan atau keunggulan dirinya, tidak hanya melihat dari sisi kelemahannya saja. WRAR juga merasakan hal yang hampir sama, yaitu menjadi lebih bisa paham dengan kelemahan dan keunggulan dirinya. Selanjutnya setelah mempelajari materi "Meningkatkan kepercayaan diri" menurut pengakuan ACU, ia dapat mengetahui apa saja yang perlu disyukuri. HIC dan WRAR menambahkan, mereka menjadi mengingat Allah terus karena mengetahui begitu banyak karunia yang diberikan Allah kepadanya. NLM juga mengaku jadi tersadar dengan arti hidup, LAF menjadi lebih bisa bersyukur karena ia bisa tahu apa yang harus disyukuri, dan HSP menjadi tidak hanya melihat sisi kelemahan dirinya saja.

Setelah subjek diajarkan cara untuk memiliki kepercayaan diri, pada sesi selanjutnya peserta didorong untuk mampu mengekspresikan diri melalui permainan ekspresikan diri dan penjelasan tentang kemampuan-kemampuan yang dimiliki orang asertif. Tujuan sesi ini dapat tercapai dibuktikan dari hasil wawancara setelah mempelajari materi "Memiliki kemampuan orang asertif" menurut pengakuan NLM, ia menjadi lebih mengerti tentang kemampuan orang asertif. HIC menambahkan, ia akan mencoba lebih baik yaitu untuk berusaha asertif karena telah mendapat patokan bagaimana ciri kemampuan yang dimiliki orang asertif.

Relaksasi merupakan sesi keenam dari Pelatihan Asertivitas Anti-bullying, tetapi sudah dikenalkan dan dilatihkan semenjak pertemuan pertama. Tujuan dari relaksasi selalu dilakukan di setiap awal kegiatan pelatihan 
agar peserta merasa lebih rileks dan nyaman, sehingga membantu peserta dalam berkonsentrasi menerima materi kegiatan. Hasil observasi menunjukkan bahwa semua peserta tampak dapat menikmati dan terlibat dengan santai pada saat pelatihan. Manfaat dari relaksasi yang dirasakan oleh peserta antara lain merasa relaks (MF dan NLM), membantu menenangkan pikiran sehingga pikiran menjadi segar dan enak (MRA), mengurangi benang kusut dalam diri (HIC), dan merasa bisa lebih damai (FNP).

Pada sesi Visualisasi Positif dengan materi tentang "Melakukan visualisasi positif" dirasa menarik oleh RVW karena merupakan pengalaman cara baru yang membuatnya semakin percaya diri. Menurut pengakuan HIC setelah mendapat materi ini bisa meningkatkan keyakinan dan kepercayaan dirinya, FNP bisa merasakan apa yang ia bayangkan, dan LAF menjadi senang bisa membayangkan dirinya akan jadi apa di masa depan.

Berdasarkan hasil observasi saat penelitian, diketahui bahwa banyak peserta yang cenderung kurang mengetahui kelebihan dirinya. Sehubungan dengan itu, peneliti mengajak peserta untuk saling mengungkapkan kelebihan atau sikap positif dari teman-temannya, diharapkan dari kegiatan ini akan meningkatkan harga diri subjek. Tujuan ini merujuk dari penjelasan Townend (2007) bahwa seseorang dapat mengembangkan kepercayaan dirinya melalui kesadaran diri dan pengakuan positif dari orang lain. Individu yang merasa positif dengan dirinya sendiri akan bisa menghargai orang lain, mampu memberi dan menerima pengakuan positif/apresiasi. Pengakuan positif akan menginspirasi dan memotivasi seseorang, karena pengakuan mengkomunikasikan pada individu bahwa prestasinya dihargai, sehingga mendorong kinerja individu tersebut semakin unggul dan lebih bersemangat. Pada saat yang sama, ia akan merasa berarti untuk orang lain, keberadaannya berharga, dan merasa terhubung lebih dekat dengan orang-orang yang telah mengakuinya. Selain itu, ilmu saraf afektif juga menjelaskan bahwa koneksi saraf baru dapat terbentuk melalui pengalaman positif dengan orang lain (Townend, 2007).

Hasil penelitian menunjukkan adanya peningkatan asertivitas yang signifikan pada peserta kelompok eksperimen. Berdasarkan analisis selama proses pelatihan, terdapat faktor-faktor yang mendukung keberhasilan penelitian menggunakan modul PEDULI ini, yaitu: Metode pelatihan, materi pelatihan, dan motivasi peserta.

Peneliti menggunakan metode pelatihan dengan model experiential learning atau pembelajaran berbasis pengalaman yang berupaya melibatkan peran serta partisipan dalam aktivitas permainan, refleksi, sharing, diskusi, ceramah, dan latihan kasus. Metode ini memberikan pengalaman belajar langsung pada peserta, memberikan kesempatan menemukan sendiri makna hasil belajarnya, serta menguji sendiri kesahihan pengalamannya itu (Supratiknya, 2011). Afiatin (2010) menambahkan bahwa aktivitas belajar yang nyata dan bermakna ini dapat memberikan kesempatan pada peserta untuk mengamati dan merasakan sendiri kegiatan yang dialaminya, meningkatkan keaktifan dan perasaan senang peserta, serta mendorong peserta untuk mengaplikasikan langsung apa yang dipelajarinya dalam kehidupan sehari-hari. Aktivitas permainan, refleksi, sharing, dan diskusi telah membuat peserta mendapat pengetahuan yang lebih dari sekedar materi yang diberikan fasilitator, serta tercipta suasana yang lebih akrab. Selain itu, dengan aktivitas sharing dan diskusi telah melatih peserta untuk berani mengemukakan pendapatnya.

Selain metode, aspek materi juga berperan dalam menunjang efektivitas modul. Materi yang disajikan dalam modul PEDULI ini dirancang untuk menarik minat peserta dengan cara memilihkan materi-materi yang berhubungan dekat dengan kehidupan pribadi peserta serta dipaparkan menggunakan contoh dalam bentuk video, permainan-permainan, dan dipraktekkan langsung. Sejalan dengan penjelasan Noah dan Ahmad (Jalil \& Mahfar, 2016) bahwa modul harus mewakili pelaksanaan dalam situasi nyata misalnya dalam bentuk permainan, olahraga, saling berdiskusi, dan lain-lain. Selain itu, pemilihan media penting untuk menarik, memotivasi, dan merangsang subjek penelitian untuk mengikuti modul. Hal ini dapat dibuktikan dari pengakuan RFH dan SR pada materi "Memahami berbagai sikap seseorang", mereka merasa tertarik dengan adanya contoh dalam bentuk video sehingga membuat terlihat jelas perbedaannya antara sikap pasif, agresif, dan asertif. Selain itu, HIC mengakui merasa tertarik mempelajari materi "Mengenal bullying", "Memahami berbagai sikap seseorang", "Mengenali dan memahami sikap dan perilaku diri sendiri", serta "Memahami tentang potensi dan konsep diri sendiri" karena berhubungan dekat dengan kehidupan pribadinya. Lebih lanjut, WRAR mengakui materi "Memiliki kemampuan orang asertif" dirasa asik dan kerjasama dengan teman terasa lebih mengena saat role play keempat ciri kemampuan yang dimiliki orang asertif. SR menambahkan, melalui materi ini ia merasa perilaku asertif itu ternyata mudah jika sudah paham. Selain itu, NLM dan WRAR mengakui materinya mudah dipahami karena dipraktekkan langsung dengan dipandu oleh fasilitator, sehingga mereka jadi bisa melakukan visualisasi positif.

Terakhir, motivasi peserta dapat dikatakan turut menunjang keberhasilan penelitian ini, meskipun tidak semua peserta termotivasi secara penuh, namun sebagian besar peserta tampak bersemangat, antusias, dan kooperatif dalam menjalani sesi pelatihan. Kebanyakan peserta merespon secara positif, terbuka dengan kondisi dirinya, dan merasa berkesan telah mengikuti pelatihan berkat dukungan pemberian reinforcement baik berupa pujian maupun hadiah selama proses pelatihan berlangsung. Hal ini tampak dari hasil observasi yaitu peserta tampak serius dan menikmati pelatihan (perhatian pada fasilitator, sikap duduk subjek yang santai, senyum, dan tertawa). Keadaan ini telah sesuai dengan penjelasan Afiatin (2010) bahwa aktivitas belajar dalam eksperiential learning memerlukan 
motivasi pribadi dalam bentuk energi, keterlibatan, dan tanggung jawab.

\section{Kesimpulan}

Berdasarkan hasil analisis data penelitian dan pembahasan dapat ditarik kesimpulan bahwa modul Pelatihan Asertivitas Anti-bullying (PEDULI) dinyatakan valid secara isi dan valid secara empirik pada penerapan terhadap 14 siswa di kelompok eksperimen. Modul tersebut dapat digunakan untuk melatih siswa agar semakin asertif dan kritis terhadap perilaku bullying.

Disarankan agar diadakan penelitian lanjutan untuk memantapkan validasi empirik pada siswa SMA negeri yang lain, siswa SMA swasta, dan juga siswa SMA beragama. Juga, penyelenggaraan modul PEDULI berikutnya sebaiknya dilakukan dalam suasana rileks dan dalam waktu yang cukup agar kegiatan dapat berjalan lebih lancar dan optimal.

\section{Referensi}

Afiatin, T. (2010). Pencegahan Penyalahgunaan Narkoba dengan Program AJI: Asertif Jaya Inovatif. Yogyakarta: Gadjah Mada University Press.

Ahmad, J., Sulaiman, T., Abdullah, S. K., \& Shamsuddin, J. (2009). Building a customized module for the treatment of drug addiction under the remedial programs to be implemented on inmates at the drug rehabilitation centers in Malaysia. US-China Education Review, 6(11), 57-64.

Ahmad, J., Amat, M. A. C., Yahaya, S. N., Yusof, R., \& Alias, S. R. (2011). The construction, validity, reliability and effectiveness of drug rehabilitation module on self-concept of female addicts and motivation achievement of male addicts in Malaysia. International Journal of Humanities and Social Science, 1(10), 217-228. Diambil dari: www.ijhssnet.com

Amawidyati, S. A. G. (2010). Pelatihan asertivitas untuk menurunkan frekuensi peristiwa bullying yang dialami oleh korban. Tesis Magister Tidak Dipublikasikan. Universitas Gadjah Mada Yogyakarta.

Ando, M., Asakura, T., \& Simons-Morton, B. (2005). Psychosocial influences on physical, verbal, and indirect bullying among Japanese early adolescents. The Journal of Early Adolescence, 25(3), 268-297. doi: 10.1177/0272431605276933

Boulton, M. J., \& Smith, P. K. (1994). Bully/victim problems in middle-school children: Stability, self-perceived competence, peer perceptions and peer acceptance. British Journal of Developmental Psychology, 12(3), 315-329. doi: 10.1111/j.2044-835X.1994.tb00637.x

Craig, W., Pepler, D., \& Blais, J. (2007). Responding to bullying: What works? School Psychology International, 28(4), 465477. doi:10.1177/0143034307084136

Erath, S. A., Flanagan, K. S., \& Bierman, K. L. (2008). Early adolescent school adjustment: Associations with friendship and peer victimization. Social Development, 17, 853-870. doi: 10.1111/j.1467-9507.2008.00458.x
Fox, C. L., \& Boulton, M. J. (2003). Evaluating the effectiveness of social skill training (SST) program for victims of bullying. Educational Research, 45, 241-247. doi: 10.1080/0013188032000137238

Fox, C. L., \& Boulton, M. J. (2005). The social skills problems of victims of bullying: Self, peer and teacher perceptions. British Journal of Educational Psychology, 75, 313-328. doi: 10.1348/000709905X25517

Fox, C. L., \& Boulton, M. J. (2006). Longitudinal associations between submissive/nonassertive social behavior and different types of peer victimization. Violence and Victims, 21, 383-400. http://dx.doi.org/10.1891/vivi.21.3.383

Hasan, A. B. P., Firmiana, M. E., Sutiasamita, E., \& Rahmawati, S. (2013). Efektivitas pelatihan anti-bullying terhadap pengetahuan penanganan kasus bullying di sekolah pada guru-guru TK Jakarta. Jurnal Al-Azhar Indonesia Seri Humaniora, 2(2), 81-88.

Hawker, D. S. J., \& Boulton, M. J. (2000). Twenty years' research on peer victimization and psychosocial maladjustment: A meta-analytic review of cross-sectional studies. Journal of Child Psychology and Psychiatry, 41(4), 441-455. doi: 10.1111/1469-7610.00629

Isaacs, J., Hodges, E. V. E., \& Salmivalli, C. (2008). Longterm consequences of victimization: A follow-up from adolescence to young adulthood. European Journal of Developmental Science, 2(4), 387-397. doi: 10.3233/DEV2008-2404

Jalil, N. I. A., \& Mahfar, M. (2016). The validity and reliability of rational emotive behavioural therapy module development for university support staff. Asian Social Science, 12(2). 129137. doi: http://dx.doi.org/10.5539/ass.v12n2p129

Kaltiala-Heino, R., Rimpelä, M., Rantanen, P., \& Rimpelä, A. (2000). bullying at school-An indicator of adolescents at risk for mental disorders. Journal of Adolescence, 23(6), 661-674. doi:10.1006/jado.2000.0351

Kolb, D. A., Boyatzis, R. E., \& Mainemelis, C. (1999). Experiential learning theory: Previous research and new directions. Department of Organizational Behavior, Weatherhead School of Management, Case Western Reserve University, Cleveland, OH.

Lee, S., \& Crockett, M. S. (1994). Effect of Assertiveness Training on Levels of Stress and Assertiveness Experied by Nurses in Taiwan, Republic of China. Issues in Mental Health Nursing, 15, 419-432. doi: http://informahealthcare.com/doi/abs/10.3109/01612849409006918

Lin, Y. R., Shiah, I. S., Chang, Y. C., Lai, T. J., Wang, K. Y., \& Chou, K. R. (2004). Evaluation of an assertiveness training program on nursing and medical students' assertiveness, self-esteem, and interpersonal communication satisfaction. Nurse Education Today, 24, 656-665. doi:10.1016/j.nedt.2004.09.004

Nansel, T. R., Craig, W., Overpeck, M. D., Saluja, G., \& Ruan, W. J. (2004). Cross-national consistency in the relationship between bullying behaviors and psychosocial adjustment. Archives of Pediatrics \& Adolescent Medicine, 158(8), 730-736. doi:10.1001/archpedi.158.8.730 
Nishina, A., \& Juvonen, J. (2005). Daily reports of witnessing and experiencing peer harassment in middle school. Child Development, 76(2), 435-450. doi: 10.1111/j.14678624.2005.00855.x

Novalia., \& Dayakisni, T. (2013). Perilaku asertif dan kecenderungan menjadi korban bullying. Jurnal Ilmiah Psikologi Terapan Fakultas Psikologi Universitas Muhammadiyah Malang, 1(1), 169-175.

Nugroho, S. (2009). Program psikoedukasi untuk meningkatkan pengetahuan dan keterampilan guru dalam menangani bullying. Tesis Magister Tidak Dipublikasikan. Universitas Gadjah Mada Yogyakarta.

Perwitasari, H. (2013). Program "circle of problem solving" untuk meningkatkan kesiapan guru merespon bullying. Tesis Magister Tidak Dipublikasikan. Universitas Gadjah Mada Yogyakarta.

Purnami, R. S., \& Rohayati. (2013). Implementasi metode experiential learning dalam pengembangan softskill mahasiswa yang menunjang integrasi teknologi, manajemen, dan bisnis. Jurnal Penelitian Pendidikan, 14(1), 97-103.

Rini, B. D. C. (2008). Pelatihan asertif untuk korban bullying pada siswa sekolah dasar. Tesis Magister Tidak Dipublikasikan. Universitas Gadjah Mada Yogyakarta.

Rini, C. L. (2014, 23 Oktober). Indonesia masuk kategori darurat 'bullying' di sekolah. Diambil dari: http://www.republika. co.id/berita/nasional/umum/14/10/23/ndvn63-indonesiamasuk-kategori-darurat-bullying-di-sekolah

Salmivalli, C., Lagerspetz, K., Björkqvist, K., Österman, K., \& Kaukiainen, A. (1996). bullying as a group process: Participant roles and their relations to social status within the group. Aggressive Behavior, 22(1), 1-15. doi: 10.1002/(SICI)1098-2337(1996)22:1<1::AID$\mathrm{AB} 1>3.0 . \mathrm{CO} ; 2-\mathrm{T}$

Salmivalli, C., \& Isaacs, J. (2005). Prospective relations among victimization, rejection, friendlessness, and children's self- and peer-perceptions. Child Development, 76(6), 1161-1171. doi: 10.1111/j.1467-8624.2005.00841.x-i1
Salmivalli, C. (2009). bullying and the peer group: A review. Aggression and Violent Behavior, 15(2010), 112-120. doi:10.1016/j.avb.2009.08.007

Sari, T. D. (2015). Aksi bullying di kalangan siswa sekolah menengah atas wilayah Surakarta tahun 2014/2015. Jurnal FKIP UNS, 5(2), 1-9. http://jurnal.fkip.uns.ac.id/index.php/ sosant/article/view/6238/4295

Setiono, V., \& Pramadi, A. (2005). Pelatihan asertivitas dan peningkatan perilaku asertif pada siswa-siswi SMP. Anima, Indonesia Psychological Journal, 20(2), 149168. http://www.anima.ubaya.ac.id/class/openpdf.php?file= 1350464574.pdf

Shadish, W., Cook, T., \& Campbell, D. (2002). Experimental and quasi-experimental designs for generalized causal inference. Boston: Houghton Mifflin Company.

Sitasari, N. W. (2012). Program pelatihan kesiapan guru untuk mengatasi perundungan dengan metode bermain peran. Tesis Magister Tidak Dipublikasikan. Universitas Gadjah Mada Yogyakarta.

Sudjana, N. (1991). Teori-teori belajar untuk pengajaran. Jakarta: Lembaga Penerbit Fakultas Ekonomi Universitas Indonesia.

Supratiknya, A. (2011). Merancang program dan modul psikoedukasi (Edisi Revisi). Yogyakarta: Universitas Sanata Dharma.

Townend, A. (1991). Developing assertiveness: Self-development for managers. London: Cengage Learning EMEA.

Townend, A. (2007). Assertiveness and diversity. New York: Palgrave Macmillan.

Weni Nur, S. (2012). Peningkatan perilaku asertif terhadap perilaku negatif berpacaran melalui pelatihan asertivitas pada siswa kelas x pemasaran 1 di smk negeri 1 Depok. Skripsi Dipublikasikan. Universitas Negeri Yogyakarta. Diambil dari: http://eprints.uny.ac.id/9575/ 